\title{
Tectonic stress field and large earthquake recurrence period in China
}

\author{
Department of Geology, Peking University, Beijing 100871, China
}

The recurrence interval of large earthquakes varies from one active fault to another as inferred from the palaeoseismic data in China. Generally speaking, the interval in eastern part of China is much longer than that in the western part, and that around the plate boundary is remarkably shorter than that in the intraplate of China. To consider the reason for the phenomenon, a mechanical model was constructed by the method of finite element numerical analysis to probe into the distribution of elastic strain energy caused by tectonic stress. The procedures to be used in this paper are: (1) to analyze the boundary condition and action pattern of force on the boundary in China and its adjacent areas by geological method, (2) to make inversion of the force acting on the boundary and the tectonic stress field in the region by finite element method based on the criterion of the maximum principal stress direction, (3) to calculate the attenuation of strain energy with the increase of distance apart from the plate boundary. Based on the attenuation pattern, the accumulative range of strain energy is converted to reach a given value (a given magnitude of large earthquake) in different parts of the research region into time or period, which is compared with the known recurrence interval of large earthquake along an active fault zone obtained by palaeoseismic method. The comparison shows that the remarkable difference of large earthquake recurrence interval between plate boundary and intraplate can be well explained by the attenuation pattern of strain energy.

\section{Introduction}

The study of large earthquake recurrence interval is significant to earthquake prediction and engineering construction. R. E. Wallace, one of the pioneers of modern paleoseismology, estimated a recurrence interval for earthquakes of different magnitude on the San Andreas fault (Wallace, 1970). He suggested that the recurrence intervals for earthquakes of $M=7-8$ are 100-1000 years. Since then, much work has been done in paleoseismology (Sieh, 1978; Schwartz et al., 1984; Hull, 1996; Lienkaemper et al., 1996; Marco et al., 1996). The recurrence intervals may be measured from several hundred years to even hundreds of thousands of years or longer (Yeats et al., 1996). For example, McCalpin et al. (1996) show that the average return time for Wasatch fault varies between 1200 and 2500 years. Bull (1996) suggests that the periodic recurrences with are at intervals of 260 years for the Alpine fault in New Zealand.

The palaeoseismic method is an effective way for inferring earthquake recurrence interval, but it needs time and money to accumulate data and it is impossible to determine the general characteristics of a large area in a short time. A mechanical model of finite element numerical analysis, therefore, has been devised in this paper to remedy the defect of palaeoseismic method. The procedures are: (1) to calculate the stress pattern of China and its adjacent areas, caused by the interaction of the three large plates: the Indian, Pacific and Philippine plates from the point of view of stress transmission and it was found out that the stress value dropped rapidly as the distance increased from the plate boundary, and the elastic strain energy also decreased from the boundary to intralplate; (2) to convert the accumulative range of strain energy to reach a given value (a given magnitude of large earthquake) in different parts of the study area into time or period based on the attenuation pattern of stress or strain energy. Suppose the value of strain energy to produce a given magnitude of large earthquake to be the same in different regions, the period for accumulating the same value of strain energy in the regions is quite different, i.e. the recurrence interval of large earthquakes varies from one part to another.

The numerical modeling of present-day stress field in China and its adjacent areas was studied by many former researchers (Wang et al., 1985 and Wang et al., 1980), but the boundary condition collected was not appropriate, i.e. the northern boundary was restrained from displacement in north and south direction, the western boundary, fixed from displacement in east and west direction, with only the southern boundary taken as free boundary. Although the pattern of the maximum compressive principal stress direction fitted fairly well with the observed data in this consideration, the distribution of stress value fell far from to the reality. The north and west boundaries are taken as infinite elements in this paper because they are not real plate boundaries, so the calculating results are more in accordance with the reality both in stress orientation and value.

\section{Some large earthquake recurrence intervals along active faults obtained from palaeoseismic data}

The earthquake forming and occurring may be considered as the process of elastic deformation and releasing strain energy. Thus a finite element model was conducted in this paper to calculate the regional stress field and elastic strain energy distribution by an elastic program for probing into the relations between strain energy and earthquake recurrence interval. In order to obtain the distribution pattern of large earthquake recurrence intervals along the main active faults in this study area and to compare it with the calculated results, the data of autochthonous recurrence periods of large earthquakes were collected along active faults observed by palaeoseismic method in the area and is listed in Table 1 and Figure 1.

The distribution pattern of large earthquake recurrence intervals can be generalized as follows based on the collected data: 
1) The recurrence intervals of large earthquakes are quite different in different area.

2) The recurrence interval period in the eastern part of China is much longer than that in the western part.

3) The interval around the plate boundary is remarkably shorter than that in the intraplate of China.

A good deal of enlightenment from the above phenomena may be gained as follows:

1) The period of large earthquake recurrence interval is the reflection of the accumulative time of strain energy.

2) The effect of the stress action of the Indian plate on China continent is much larger than that of the Pacific and the Philippine plates.

3) It is an effective way to estimate large earthquake recurrence interval from the distribution of elastic strain energy.

Table 1 The recurrence intervals of large earthquakes along some active faults in the continent of China ias nferred from the palaeoseismic data.

\begin{tabular}{|c|c|c|c|c|}
\hline Active fault & Site & Ms & Period(years) & ) Reference \\
\hline Red river & Dali, Yunnan & 6.8 & 200 & Guo, 1986 \\
\hline Xiaojiang & $\begin{array}{l}\text { Songming, } \\
\text { Yunnan }\end{array}$ & 8.0 & 900 & Chen, 1988 \\
\hline Xianshuihe & Luhuo, Sichuan & 7.6 & 600 & Ye, 1996 \\
\hline Changma & Changma, Gansu & 7.6 & 2000 & Guo, 1992 \\
\hline Altun & Minfeng, Xinjiang & 7.7 & 1670 & Xing, 1992 \\
\hline Haiyuan & Haiyuan, Ningxia & 8.5 & 1900 & Cheng, 1984 \\
\hline Ertai & Fuyun, Xinjiang & 8.0 & 3300 & Ye, 1996 \\
\hline Kashihe & Nileke, Xinjiang & 8.0 & 2300 & Feng, 1987 \\
\hline Huashan & Huaxian, Shaanxi & 8.0 & 2500 & Zhang, 1989 \\
\hline Xiadian & Sanhe, Hebei & 8.0 & 6500 & Ran, 1997 \\
\hline Cangdong & Tangshan, Hebei & 7.8 & 7500 & Wang, 1984 \\
\hline
\end{tabular}

\section{The effect of boundary condition and loading force pattern on the intrablock stress distribution of China}

The numerical modeling of present day tectonic stress field in China and its adjacent area was done by former researchers (Wang et al., 1985 and Wang et al., 1980). Although the calculating results were well fitted with the trajectory of P-axis obtained from focal mechanism solution, the distribution of stress value was inconsistent with the facts. The stress measurement shows that the stress value in the western part of China is much larger than that in the eastern part ( $\mathrm{Li}$, et al. 1986). The studies on active faults reveal that the slip rate of active faults in the west $(>10 \mathrm{~mm} / \mathrm{yr})$ is much faster than that in the east $(<1$ $\mathrm{mm} / \mathrm{yr}$ ) (Guo et al., 1986; Chen et al., 1988; Ye et al., 1996; Guo et al., 1992; Xing, 1992; Cheng et al., 1984; Feng, 1987; Ran et al., 1997 and Wang, 1984). Therefore, it can be infered from the above observed facts that the pressure of the Indian plate on China continent is much larger than that of the Pacific plate and the Philippine plate. The distribution of stress value calculated by Wang et al. (1985) and Wang et al. (1980), however, shows no China. remarkable difference between the west and the east except along active fault zones. The reason might be that the boundary condition selected was inconsistent with the reality.

To analyze the influential factors of stress distribution, a test was made as following:

Choosing a rectangular block $(11 \mathrm{~cm}$ in length and $8 \mathrm{~cm}$ in width) and restraining the lower boundary and putting pressure on the upper boundary, we can find the difference of stress distribution in the rectangle as changing the loading length on the upper side (Figure 2a).

The curves of stress distribution along line $\mathrm{AB}$ in Figure 2a are drawn in Figure 2b. Of them, the curve (1) is gotten by putting concentrated force on point A, the curve (7) expresses the stress distribution by loading on the whole surface of the upper boundary. These are the two extreme conditions. Curves (2) - (6) lie between them and express the loading lengths, taking point $\mathrm{A}$ as the center, to be 1 $\mathrm{cm}, 3 \mathrm{~cm}, 5 \mathrm{~cm}, 7 \mathrm{~cm}$ and $9 \mathrm{~cm}$ respectively. We can tell from Figure $2 b$ that the stress distribution is all the same in the whole area when even loading is put on the whole upper side which corresponds to even stress state, and the stress value rapidly drops as the distance increases apart from the plate boundary when concentrated loading is put on the center of the upper surface corresponding to the plate boundary. The stress distribution between the two extreme conditions shows the stress attenuation from plate boundary to far end and the attenuation rate becomes high with the conditions changing from the state of curve (7) to that state of curve (1).

Considering the above test, the conditions of the real plate boundaries related to China continent were analyzed. The boundary length selected for calculation, on the one hand, is only a part of real plate boundary, and how to give the restraints in the two ends in order to make it equivalent to the reality is worth of note. On the other hand, the range and orientation of applied force are changeable on the boundary of the model. The distribution of applied force on the collision boundary between the Indian plate and the Eurasian continent is quite uneven, i.e. the applied force around the Pamirs and Assam on the western and eastern ends respectively of the northern boundary of the Indian plate may be larger than that on other places of the boundary. The pressure of the Philippine plate to the Asian continent might be the strongest in Taiwan area along the whole boundary. The applied force may propagate in a progressive decreasing pattern from plate boundary to interior, the stress attenuation pattern superimposes on the even stress pattern produced by relative small force evenly distributed on the whole boundary, thus the result must still be uneven. The combined action of the Indian,

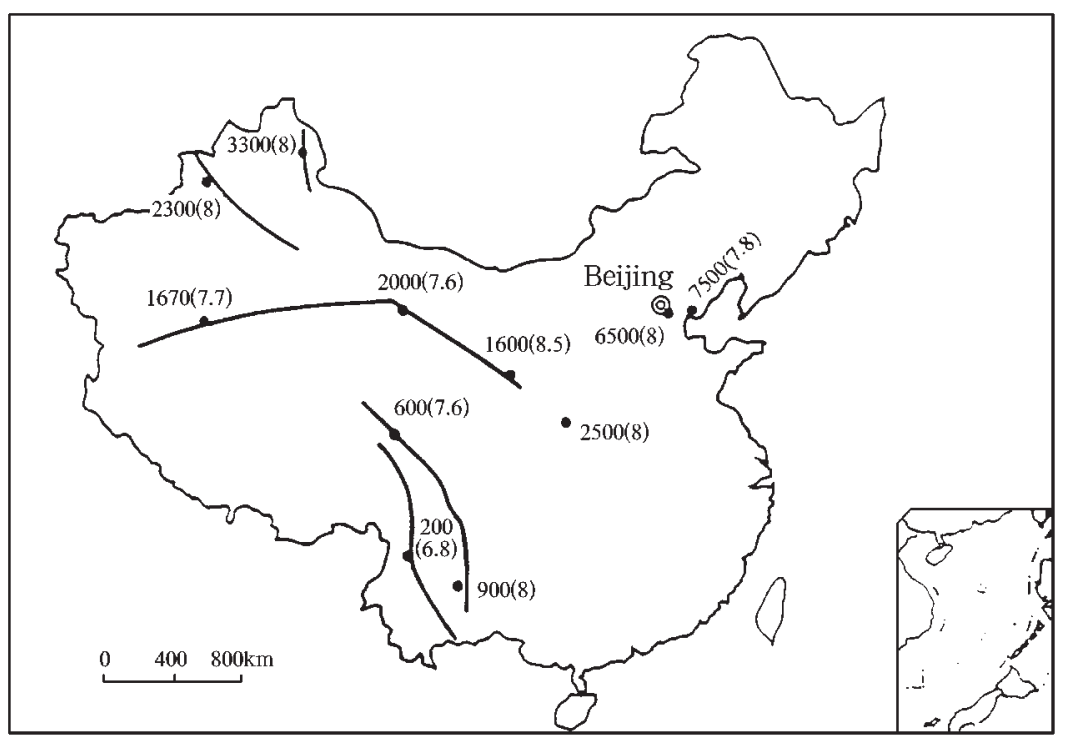

Figure 1 The distribution of recurrence intervals on some active faults in the continent of China. black solid circle: research site, 6500 (8): interval of large earthquake recurrence (magnitude), black thick line: main active faults in 
the Pacific and the Philippine plates on China continent and its adjacent areas and the different distribution of the range and orientation of the boundary force must make the stress complicatedly distributed in the continent interior, therefore the complicated pattern must be obtained through numerical calculation and can not be gotten by simple analysis.

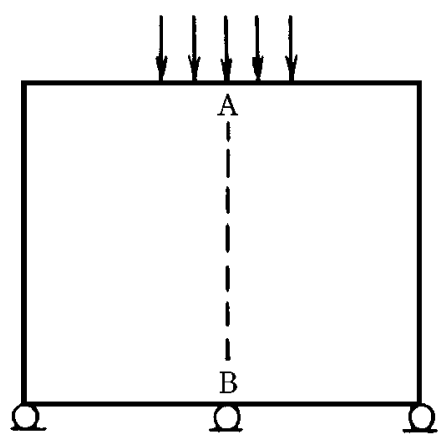

(a)

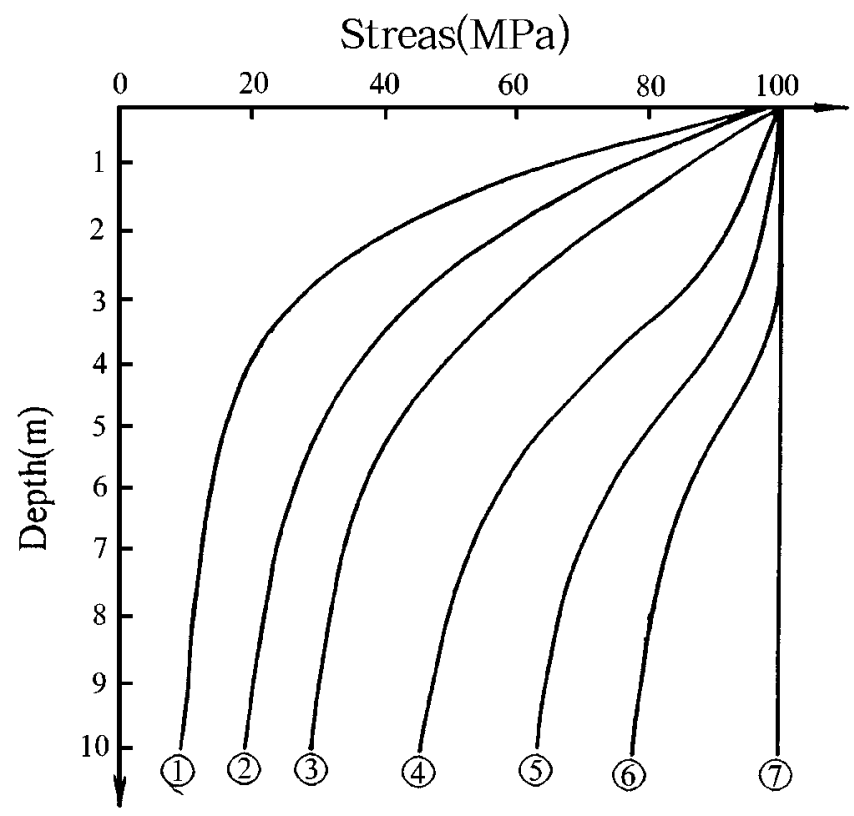

(b)

Figure 2 Stress distribution along depth in different loading pattern. (a) boundary condition and loading pattern: fixing the lower side and loading on the upper side (the lengths of loading side on point $A$ are $1 \mathrm{~cm}, 3 \mathrm{~cm}, 5 \mathrm{~cm}, 7 \mathrm{~cm}$ and $9 \mathrm{~cm}$ respectively, taking point $A$ as the center). (b) intrablock attenuation curves: the attenuation rate is from high [curve (1)] to low [curve(6)] and to zero [curve (7)].

\section{The conversion of present-day tectonic stress field and pattern in China and its adjacent areas.}

\section{Model}

Based on the above analytic result, we conduct a calculating model as shown in Figure 3.

\section{The modeling area and finite element division}

The modeling area includes China and its adjacent areas, taking the boundary between the Eurasian plate and the Pacific and the

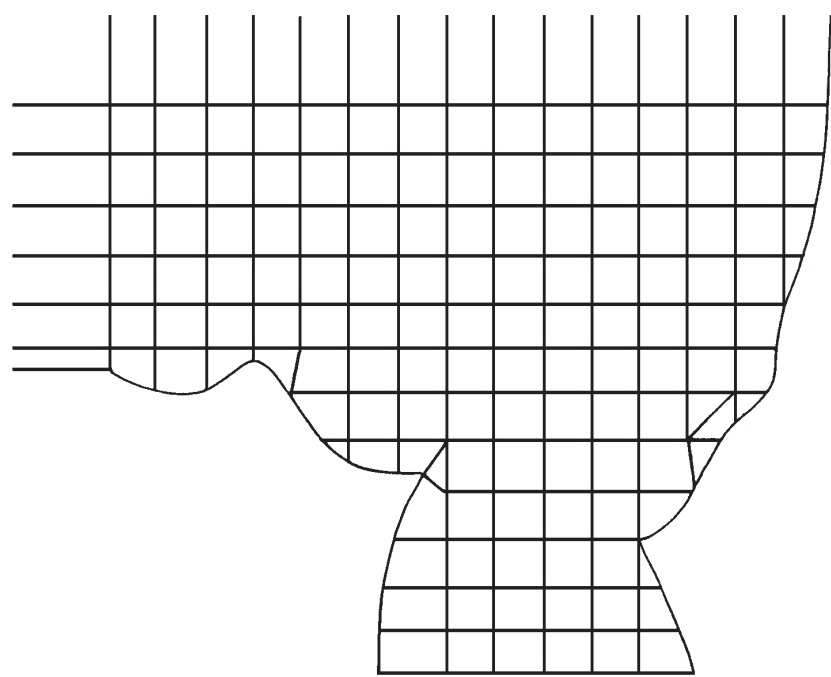

Figure 3 The grid of the model.. the forced boundaries: the southwestern side and the eastern side; the free boundary: the southern side; the infinite boundaries: the western side and the northern side.

Philippine plates as the eastern side, the boundary between the Indian plate and the Eurasian plate as the southeastern side, the western, northern and southern sides are divided based on longitude and latitude lines. The whole region is divided into 185 nodes, 139 isoparametric finite elements and 21 infinite elements.

The material properties selected for the model

The Young's modulus E $=5 \times 10^{4} \mathrm{MPa}$ and the Poisson's ratio $v=0.25$ are selected for all the elements of the model.

\section{The boundary restraint}

The northern and western sides stretch boundlessly towards north and west, not real plate boundaries, so the displacement in the western and northern boundaries can not suddenly become zero. To express the process of stress attenuation, a row of infinite elements is added on the northern and western boundaries respectively. The effect of these elements is to cause the displacement to become zero gradually as the distance increases to far end (regarding as infinite distance place in the view of mathematics), so the exponential attenuation of displacement can reach from the boundaries to infinite distant place. The southern side may be taken as free boundary. The southwestern and eastern sides are real plate boundaries and taken as forced boundaries.

\section{The force acted on the plate boundaries}

a. The action of the Indian plate: The Indian plate moves towards north-northeast to push on the Eurasian plate boundary, so the azimuth of the pressure force is taken as $20^{\circ} \mathrm{C}-30^{\circ} \mathrm{C}$. The force is distributed unevenly on the boundary and is thought to be larger in the Pamirs and Assam than that in the other parts.

b. The action of the Philippine plate: The Philippine plate moves towards northwest (about $300{ }^{\circ} \mathrm{C}$ in azimuth) and the action force is relatively larger in Taiwan than that in the other parts.

c. The action of the Pacific plate: The azimuth of the action force is taken as $260{ }^{\circ} \mathrm{C}$ and the force is thought to be relatively larger on the convex parts of the plate boundary than that in the other parts.

The relative ranges of the action force from the three plates are deduced and adjusted based on the comparison of the principal stress trajectory obtained by calculation with the P-axis orientation gotten by focal mechanism solution. The calculated trajectory may differ greatly from the observed data if the ranges of the action force from the three plates are inappropriately selected according to the analysis 


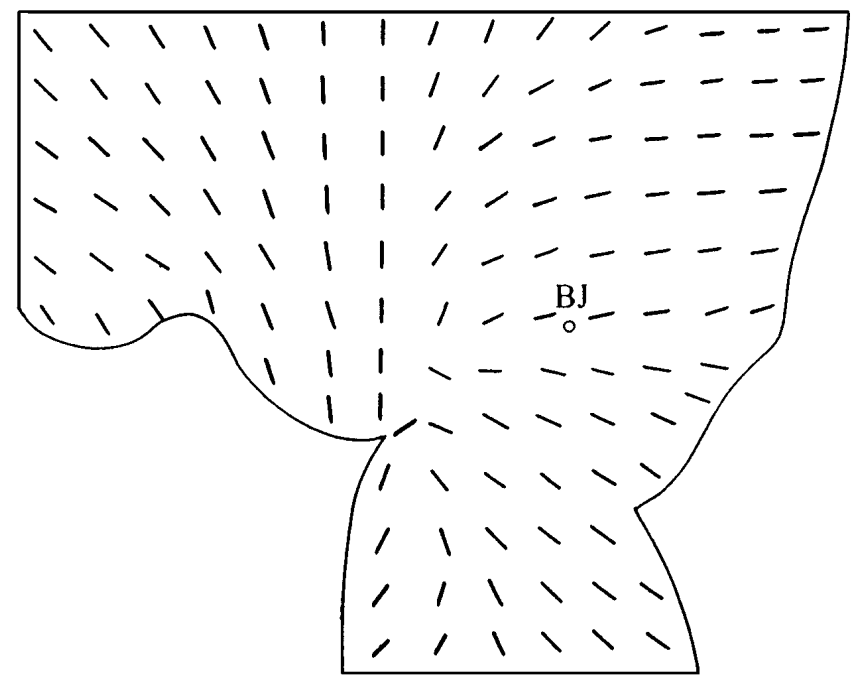

Figure 4 Calculated trajectory of the maximum compressive principal stress axis. Dash line shows the direction of the maximum compressive principal stress axis.

from a lot of calculating models. For example, if the action force of the Indian plate taken is too large, the orientation of the maximum compressive principal stress axis in North China would not be well fitted with the reality (NNE direction). On the other hand, the trajectory would strike ENE direction in the western part of China (approximately north-south direction in fact) if the force from the Pacific plate is chosen too large. After adjusting the model for many times, the calculated trajectory is well fitted with the reality when taking the value of the force from the Indian plate as two times as that from the other two plates (Figure 4).

It seems that the action forces from the three plates should be equal because the moving velocities of the three plates are all about $5 \mathrm{~cm} / \mathrm{a}$. The boundaries of the Pacific and the Philippine plates, however, are subduction ones and the great part of the force must be consumed on the subduction boundary surface, and therefore there is only a small part of the force pushing horizontally on the Eurasian plate boundary. Conversely, the boundary between the Indian and the Eurasian plates is a collision one and the horizontal pushing force is the main component. Therefore, the effect of the Indian plate on China continent is much larger than that of the other two plates. Although the seismicity on the Pacific and the Philippine plate boundaries is quite strong and the earthquake recurrence interval is also quite short, most of the earthquakes are concentrated on the subduction zone, whose effect on China continent is very small and is not considered in this paper.

\section{Calculated result of elastic strain energy}

The isopleth of elastic strain energy can be obtained from the calculated model and drawn as in Figure 5. We can tell from the distribution of the isopleth that the value of elastic strain energy is the largest along the boundary between the Indian and the Eurasian plates, about $300 \mathrm{erg} / \mathrm{cm}^{3}$ (up to $600 \mathrm{erg} / \mathrm{cm}^{3}$ in some segments) and gradually attenuates towards the east, about $20 \mathrm{erg} / \mathrm{cm}^{3}$ in North China. The value of elastic strain energy is relatively large along the eastern boundary between the Eurasian plate and the Pacific and the Philippine plates, around $30 \mathrm{erg} / \mathrm{cm}^{3}$ and rapidly attenuates towards the west. So a low value zone trending north and south appears in the eastern part of China between the two ends of the elastic strain energy attenuation from the Indian plate boundary and the Pacific and the Philippine plate boundaries. The attenuation pattern is well fitted with the observed data from stress measurement and slip rate of active faults, so the action force is mainly from the Indian plate which pushes towards the north-northeast, about as 2 times as the force value from the Pacific and the Philippine plates.
Suppose the elastic strain energy for a magnitude 8 earthquake being the same $\left(6 \times 10^{23} \mathrm{erg}\right)$ in different areas, the earthquake recurrence interval for a magnitude 8 earthquake in each part can be obtained as a quotient from the required value $\left(6 \times 10^{23} \mathrm{erg}\right)$ of elastic strain energy divided by the product of the calculated energy value per unit volume per year times the earthquake volume deduced by seismotectonic method. The values of elastic strain energy shown in Figure 5 and their corresponding period of large earthquake recurrence interval are listed in Table 2.

The interval for a magnitude 8 earthquake is around 7000 years in Beijing area and about 1000-2000 years near the Indian plate boundary, which is well fitted with the observed data. The interval in Taiwan area, however, seems to be 5000 years, which is inconsistent with the facts. The reason is that most of the earthquakes there occurred in the subduction zone which was not considered in this paper.

\section{Discussions}

1) The intervals discussed here are mainly for the great earthquakes of about magnitude 8 , and the periods for the earthquakes of magnitude 7 or less must be much shorter than that of magnitude 8 earthquakes.

2) The intervals discussed in this paper mean the autochthonous periods, not the synthetic intervals in a whole area. The so called autochthonous periods mean that the focuses of two large earthquakes are so close to each other that the extreme zones of the two events coincide or partly overlap each other. The synthetic interval for an area such as North China means that the repeated periods of earthquakes in different magnitude occurred on many active faults, i.e. the interval between two relatively active periods with relatively frequent earthquakes caused by many active faults within the area, separated by a relatively quiet period. The synthetic interval in North China is thought to be several hundred years ( $\mathrm{Lu}$, et al., 1985).

3) Judging from the calculated results and palaeoseismic data, the general character of the intervals is that the periods gradually become longer from the plate boundaries to the plate interior of China, but they are still different to some extent, which may be caused by the collected pure elastic model here. In fact, the stress has acted on the rocks for several thousand years that the rock may have some rheological behavior, but the factor of stress relaxation is not considered in this paper.

4) The occurrence of large earthquakes requires two factors: accumulation of elastic strain energy and strong strength for rocks to

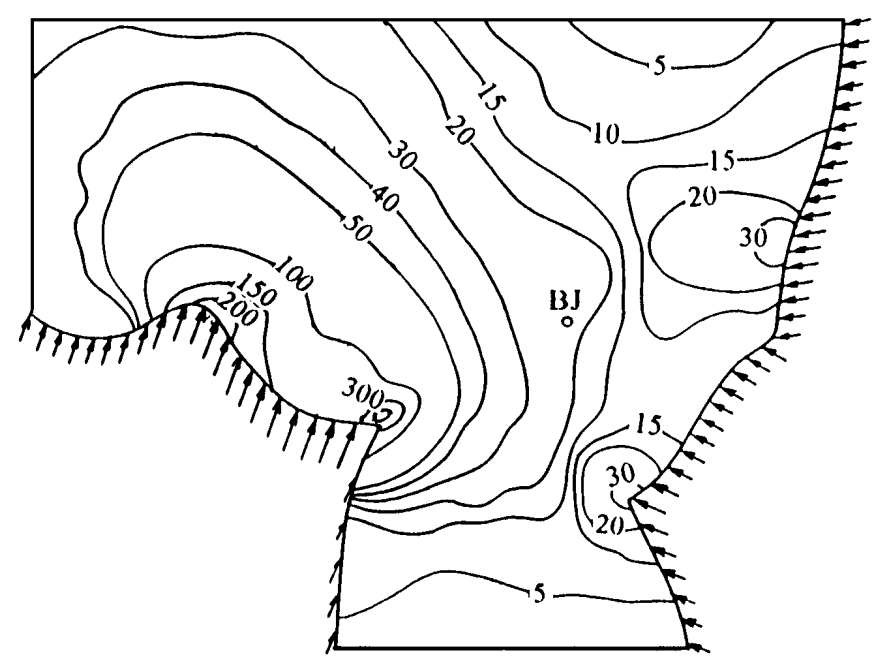

Figure 5 Attenuation pattern of elastic strain energy from plate boundary to plate interior. arrow: direction of action force; thin line: isopleth of elastic strain energy; number: value of elastic strain energy (unit: erg/yr). 
Table 2 Values of elastic strain energy and their corresponding period of large earthquake interval.

\begin{tabular}{cccc}
\hline $\begin{array}{l}\text { Strain energy } \\
\text { (erg) per unit } \\
\text { volume per year }\end{array}$ & $\begin{array}{c}\text { Recurrence } \\
\text { interval } \\
\left(10^{3} \text { years }\right)\end{array}$ & $\begin{array}{c}\text { Strain energy } \\
\text { (erg) per unit } \\
\text { volume per year }\end{array}$ & $\begin{array}{c}\text { Recurrence } \\
\text { interval } \\
\left(10^{3} \text { years }\right)\end{array}$ \\
\hline 5 & 15 & 50 & 4.5 \\
10 & 10 & 100 & 3.1 \\
15 & 8.2 & 150 & 2.5 \\
20 & 7 & 200 & 2.2 \\
30 & 5.7 & 300 & 1.8 \\
40 & 5 & 600 & 1.3 \\
\hline
\end{tabular}

resist deformation. The model only considered the relations between the elastic strain energy accumulation and large earthquake recurrence interval without involving rock strength. If a large block is uniform and very strong, i.e. rigid block in terms of geology, a large earthquake can not occur there. The continent of China has several large rigid blocks such as Tarim block in the western part of China, Ordos and Alxa blocks in the west of North China and South China block in South China. So the isopleth of elastic strain energy should be discontinuous if the rigid blocks are not considered.

The further study should consider the inhomogeneity of blocks and the effect of active faults on the distribution of elastic strain energy.

\section{References}

Bull, W. B., 1996, Prehistorical earthquakes on the Alpine fault, New Zealand: J. Geophys. Res., v. 101, B3, pp.6037-6050.

Chen, R. and Li, Ping., 1988, Slip rates and earthquakes recurrence intervals of the western branch of the Xiaojiang fault zone: Seismology and Geology. v. 10, pp. 1-13

Cheng, S., Peng, G. and Li, H., 1984, Offset gullies and recurrence time of M8.5 strong earthquakes along the fault zone of northern piedmont of Nanhua Mountain, Haiyuan, Ningxia: Seismology and Geology. v. 6. pp. 25-37.

Feng, X., 1987, Paleoseismological study for Kaxhe fault zone, Xingjiang: Seismology and Geology, v. 9, pp. 74-77.

Guo, S., Zhang, J., Li, X., Xiang, H., Chen, T. and Zhang, G., 1986, Fault displacement and recurrence intervals of earthquakes on the northern segment of the Honghe river fault zone, Yunnan Province: Seismology and Geology. v. 8. pp. 77-90.

Guo, J. and Hou, Z., 1992, Paleo-earthquake events in the Changma fault zone. in Lanzhou Seismological Institute of State Seismological Bureau (ed.), Changma active fault zone: Beijing, Seismological Press, pp.161-184.

Hull, A. G., 1996, Paleoseismology from coastal environments, for the Paleoseismology Workshop of 30 th IGC. Beijing, 39-40.

Lienkaemper, J. J. and Borchardt, G., 1996, Holocene slip rate of the Hayward fault at Union City, California: J. Geophys. Res, v.101, B3, pp. 6099-6108.

Li, F. and Liu, G., 1986, The present state of stress in China and related problems. Acta Seismologica Sinica, v. 8, pp.156-171.

Lu, Y., Chen, Z., Wang, B., Liu, P., Liu, W. and Dai W., 1985, Seismological method of earthquake prediction: Beijing, Seismological Press, $18-24$.

Marco, S., Stein, M. Agnon, A. and Ron, H., 1996, Long-term earthquake clustering: A 50 000-year paleoseismic record in the Dead Sea Graben: J. Geophys. Res, v. 101, B3, pp. 6179-6191.

McCalpin, J. P. and Nishenko, S. P., 1996, Holocene paleoseismicity, temporal clustering, and probabilities of future large $(M>7)$ earthquakes on the Wasatch fault zone, Utah: J. Geophys. Res, v. 101, B3, pp.6233-6253.

Ran, Y., Deng, Q., Yang, X., Zhang, W., Li, R. and Xiang, H., 1997, Paleoearthquakes and recurrence intervals on the seismological fault of 1679
Sanhe-Pinggu M8 earthquake, Hebei and Beijing: Seismology and Geology. v. 19, pp. 193-201.

Schwartz, D. P. and K. J. Coppersmith., 1984, Fault behavior and characteristic earthquakes: Examples from the Wasatch and San Andreas faults: J. Geophys. Res. v. 89, pp.5681-5698.

Sieh, K. E., 1978, Pre-historic large earthquakes produced by slip on the San Andreas fault at Pallett Creek, California: J. Geophys. Res. v. 83, pp.3907-3939.

Wallace, R. E., 1970, Earthquake recurrence intervals on the San Andeas fault. Geol. Soc. Am. Bull. v. 81, pp. 2875-2890.

Wang, R. and Liang, H., 1985, Inverting the stress field of eastern Asia by the method of superposition. in Ma Zongjin (ed.), A collection of geological papers for international exchange: Beijing, Geological Publishing House, Beijing, 29-35.

Wang, S. and Chen, P., 1980, A numerical simulation of the present tectonic stress field of China and its vicinity: Acta Geophysica Sinica, v. 23 , pp.35-45.

Wang, T. and Li, J., 1984, The recurrence intervals of the strong earthquakes in Tangshan: Seismology and Geology, v.6, pp.77-83.

Xing, C., 1992, Paleo-earthquake events in the Altun active fault zone. in Project Group of Lltun active fault zone (ed), Altun active fault zone: Beijing, Seismological Press, pp.161-184.

Ye, W., Xu, X. and Wang, L., 1996, Quantitative relationship between surface rupture parameter, earthquake magnitude and recurrence interval for surface-rupturing-earthquakes in west China: Seismology and Geology, v. 18, pp $37-44$.

Yeats, R. S. and Prentice, C. S., 1996, Introduction to special section: Paleoseismology: J. Geophys. Res., v. 101, B3, pp.5847-5853.

Zhang, A., Mi, F. and Chong, J. 1989, Deformation relics of the 1556 Huaxian (Shaanxi, China) great earthquake and the study of paleoseismicity on the frontal fault zone of the Huashan Mts: Seismology and Geology, v.11, pp.71-81.

Liang Haihua is Associate Professor and Director of the Seismotectonics Section, Department of Geology, Peking University. He was educated in Peking University where he completed both his undergraduate and master degrees, and further studied in the Victoria University of Wellington, New Zealand from 1988-1989. He is currently engaged in the study of seismotectonics and geodynamics.

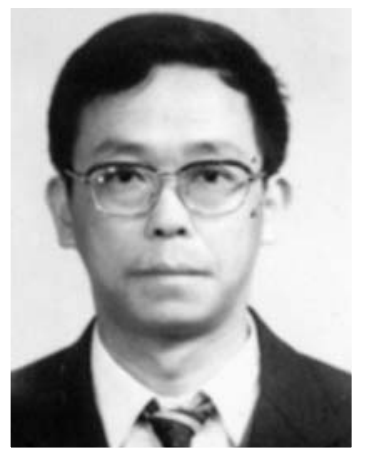

Hou Jianjun was educated at Peking University where he completed both his undergraduate and doctoral degrees in active tectonics. He works as an Associate Professor in the Department of Geology, Peking University.

Liu Shuwen is Associate Professor in Petrology. He was educated in Changcun College of Geology where he completed both his undergraduate and doctoral degrees. His research interest includes the study of deformation and metamorphism of ductil shear zone.

Chang Zufeng, Engineer, graduated from Department of Geology, Peking University in 1987 and worked on the Xiaolangdi Project on the Yellow River. Currently, he is a graduate student at Peking University. 